\title{
Modeling the Negotiation of Agents in MAS and Predicting the Performance - an SPE Approach
}

\author{
S. Ajitha \\ Ramaiah Institute of Bangalore-54, India \\ E-mail: ajithasankar@gmail.com
}

Keywords: MAS, negotiation, conditional probability, SPE, work load

Received: July 15, 2019

\begin{abstract}
Software performance engineering(SPE) process starts at the early stages of software development life cycle which helps to develop software that meets the performance requirements on time and budget. MultiAgent Systems(MAS) are comprised of one or more agents who coordinate each other to accomplish some task. The coordination can be achieved through cooperation and negotiation. In the early development stages measuring the negotiation workload and predicting the performance remains an important but largely unsolved problem. The problem of uncertainty regarding the negotiation workload is required to be addressed by estimation techniques. Hence, in this research we developed a probabilistic model for the negotiation scenario among the agents in a given time horizon. The negotiation workload obtained from the probabilistic model is integrated with the representative workload of the agents for predicting the performance of agents in MAS. The tool SMTQA is used for obtaining the performance metrics. Analysis of the execution environment is done by considering various configurations in the hardware resources based on the dynamic workload of the negotiation agents over a time horizon. From the sensitivity analysis, the bottleneck resources are identified and suggestions for improvement are proposed. Povzetek: Predstavljena je izvirna metoda za ocenjevanje in napovedovanje delovanja večagentnih sistemov.
\end{abstract}

\section{Introduction}

A Multi-Agent System (MAS) is usually understood as a system composed of interacting autonomous agents. MAS have been employed successfully in a number of scenarios. The important characteristics of the agents which distinguish it from an object are Autonomous, Cooperation, Goal oriented, Adaptability, Mobility, Negotiation etc. Many articles on MAS have been mainly concerned with functional characteristics such as coordination, rationality and knowledge modeling. The nonfunctional characteristics also have the equal importance as the functional characteristics for any software system [1-5].

This research aims at making a contribution towards the non-functional characteristics Performance of agents in a MAS by considering the negotiation character of agents. Software Performance Engineering (SPE) is a method for constructing software systems to meet the performance objectives at the early stages of Software Development Life Cycle (SDLC). In SPE, system does not exist so it is not possible to develop the work load parameters from measurement data. Therefore, models of the system are used to collect the data required to predict the performance. The different data required for the SPE approach are Workload scenarios, Performance goals, Software Design concepts, Execution environment and Resource usage estimates [5-7].

The performance prediction of agents by considering the cooperation character of agent the authors have published different articles in [8-11]. In the early development stages measuring the negotiation workload and predicting the performance remains an important but largely unsolved problem. The problem of uncertainty regarding the negotiation workload is required to be addressed by estimation techniques. Hence, in this chapter a model for the negotiation scenario among the agents in a given time horizon is developed. The fitness function which represents the fitness of the agent in the negotiation scenario among ' $n$ ' agents in MAS is considered while framing the model. The negotiation workload obtained from the probabilistic model is integrated with the representative workload of the agents for predicting the performance of agents in MAS [12-14].

The tool SMTQA is used for obtaining the performance metrics. The execution environment is analyzed by considering various configurations in the hardware resources based on the dynamic workload of the negotiation agents over a time horizon. From the sensitivity analysis, the bottleneck resources are identified and suggestions for improvement of the software are made [15].

\section{Methodology}

A methodology is proposed to model the negotiation scenario of agents in a MAS using probabilistic approach. This is based on the methodology discussed for the 
distributed systems in [15]. Let $t \in\left[t_{0}, T+t_{0}-1\right]$ be the interval, where $\mathrm{T}$ be the number of intervals, $t_{\mathrm{o}}$ be the initial interval of the given time horizon. Let $S_{T}$ be the negotiation services that are considered to be executed during the $\mathrm{T}$ intervals. With these assumptions, we have devised the methodology as follows,

- Developing a mathematical model for demand of negotiation services over a given time horizon

- Modeling the resources in the execution environment

- Modeling the variations (alternate designs) in the execution environment

- Identifying bottleneck resources and improving the performance by sensitivity analysis

\subsection{Modeling of demand of negotiation services}

Consider a MAS 'A' with ' $n$ ' number of agents. Let $S_{T}$ be a set of negotiation services that to be executed during the $\mathrm{T}$ time intervals.

Let $S_{T}=\left\{S_{1}, S_{2}, S_{3}, \ldots \ldots . S_{m}\right\}$ be the negotiation services.

Let $\mathrm{W} 1, \mathrm{~W} 2, \mathrm{~W} 3, \ldots \ldots . \mathrm{Wm}$ be the size (representative workload) of the negotiation services.

Let Pijk ( $\mathrm{t}$ ) be the probability that agent ' $i$ ' communicates with the agent ' $j$ ' with the work load of $\mathrm{Wk}$ at the time interval $\mathrm{t}$. The sum of these Pijk(t) over $\mathrm{k}$ equals 1 .

Each negotiation service that can be occurred in the interval $t \in\left[t_{0}, T+t_{0}-1\right]$, is characterized by:

- $\mathrm{P}_{\mathrm{ijk}(\mathrm{t}), \mathrm{e}}-$ probability of occurrence of the $\mathrm{e}^{\mathrm{th}}$ negotiation primitive of those specified at time interval $\mathrm{t}$

- $D_{t, e}^{S}$ - expected demand for each negotiation services $\mathrm{s} \in S_{T}$, if the $\mathrm{e}^{\text {th }}$ primitive occurs among those specified at time interval $\mathrm{t}$.

Based on such specification of expected primitives, $s_{t}$ demand scenarios can be generated in each interval $t$, where $p_{i j, s}(\mathrm{t})$ be the probability that $s^{\text {th }}$ scenario occurs at time $t$ when agent ' $i$ ' negotiates with the agent ' $j$ '.

In the first period $t_{0}$ :

$S_{t_{0}}=E_{t_{0}}$

while in the following interval $t \in\left[t_{0}, T+t_{0^{-}} 1\right]$, the number of scenarios can be recursively computed as:

$$
S_{t}=E_{t} . S_{t-1}
$$

Each workload scenario can be defined as the occurrence of one event at period $t$ given one scenario in the previous period $t-1$. Definition of the demand scenarios based on the specification of six events over a time horizon constituted of three intervals is given in Table 1 .

\begin{tabular}{|c|c|c|c|}
\hline Period & Event & Probability & Demand \\
\hline 0 & 1 & $\mathrm{p}_{1}$ & $\mathrm{D}_{1}$ \\
\hline & 2 & $\mathrm{p}_{2}$ & $\mathrm{D}_{2}$ \\
\hline 1 & 3 & $\mathrm{p}_{3}$ & $\mathrm{D}_{3}$ \\
\hline & 4 & $\mathrm{p}_{4}$ & $\mathrm{D}_{4}$ \\
\hline 2 & 5 & $\mathrm{p}_{5}$ & $\mathrm{D}_{5}$ \\
\hline & 6 & $\mathrm{p}_{6}$ & $\mathrm{D}_{6}$ \\
\hline
\end{tabular}

Table 1: Definition of the demand scenarios.

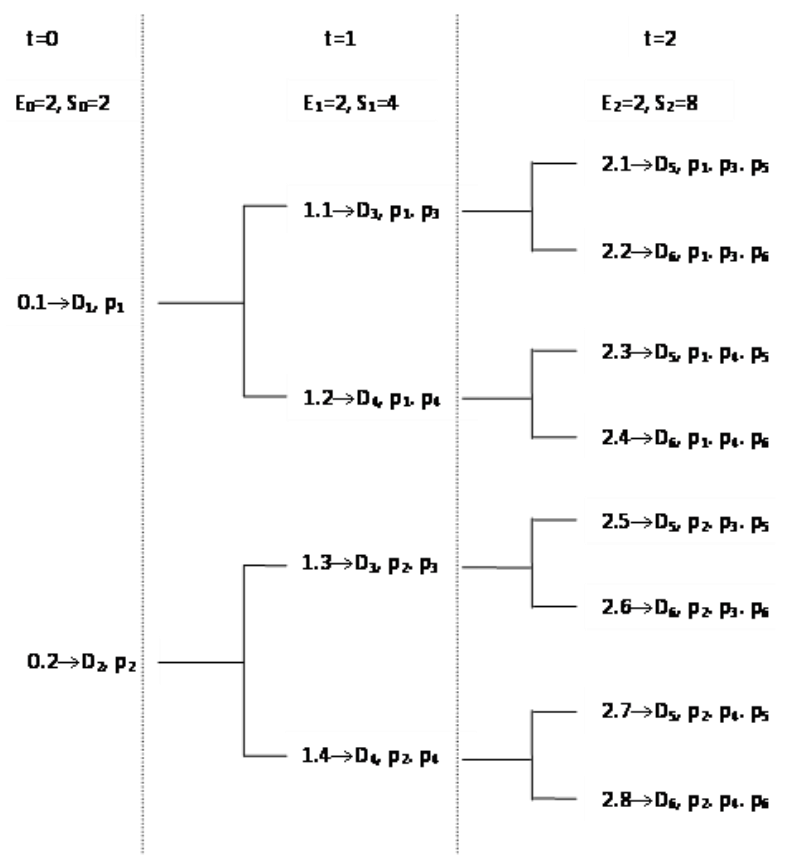

Figure 1: Conditional probability tree for the workload scenario.

\subsection{Calculation of workload}

The model is simulated by considering three time intervals such that for a given time interval $t, t \in[0,2]$. The state (negotiation scenario) of the application in time $t$ depends on the state (negotiation service scenario) at the time interval $t-1$ and the type of the request arrived at $t$. Hence the scenarios of the negotiation service are considered as states of the software application and the pattern of execution of negotiation services are modeled using the UML, State Chart Diagram. The Figure 2 to Figure 4 represent the workload to be executed during the different time duration. The negotiation services which are having a very less workload are executed during time $t=0$. During the time $\mathrm{t}=1$ the negotiation services having a higher workload are executed. At time $\mathrm{t}=2$, the negotiation services having an average workload are executed. From Figure 5 , it is observed that agent a1 and agent a3 are negotiating more with agent a4. Also agent a2, agent a4, agent a5 are negotiating more with agent a3. 


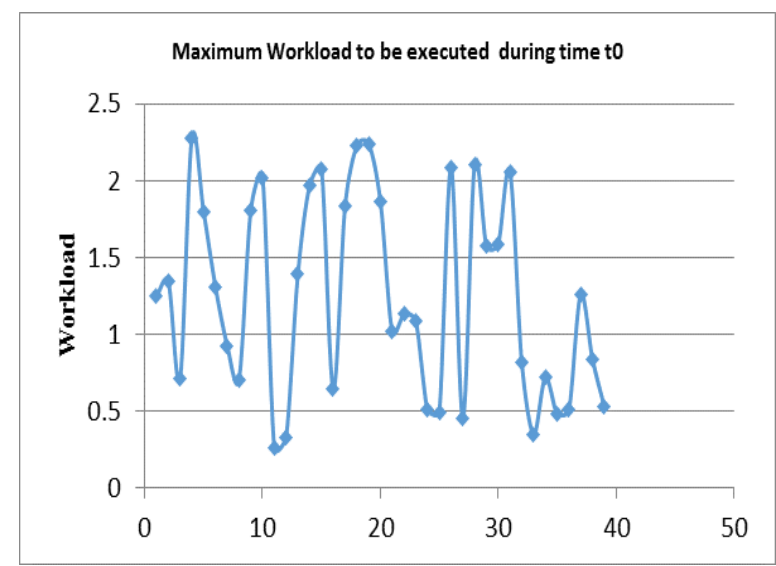

Figure 3: Work Load at Time t0.

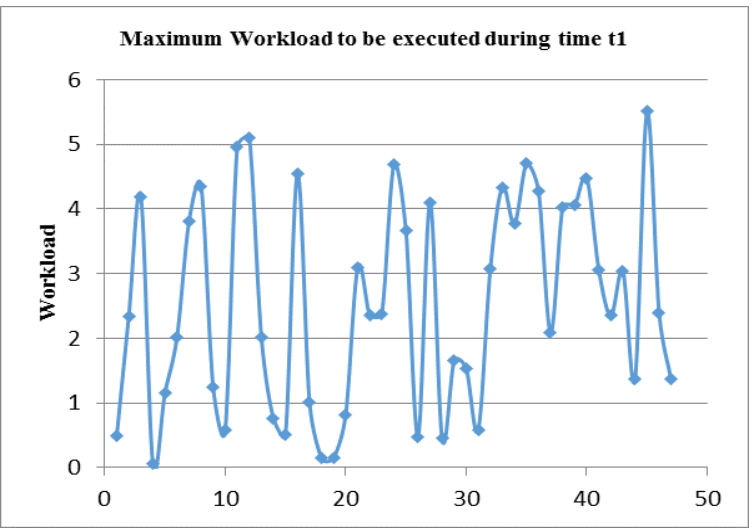

Figure 4: Work Load at Time $\mathrm{t} 1$.

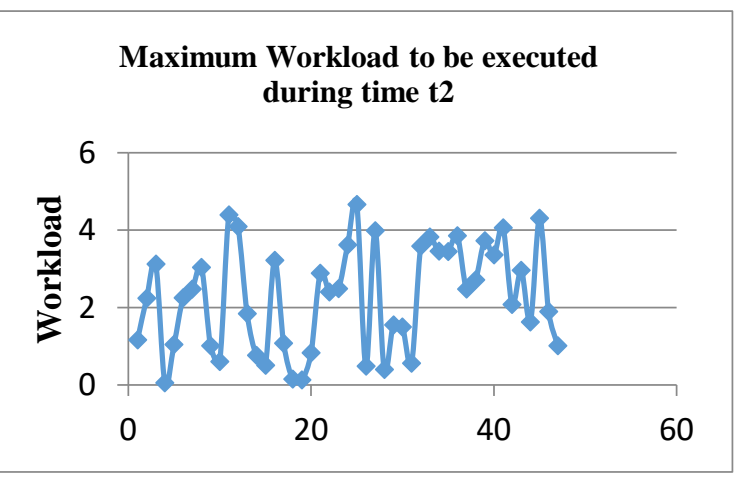

Figure 5: Work Load at Time t2.

\subsection{Simulation results}

The scenarios of the negotiation primitives are simulated using the tool SMTQA, and the performance metrics are obtained and tabulated in Table 2. The columns in the table represents average response time (Avg Resp Time), average service time (Avg Serv Time), average waiting time (Avg Wait Time), probability of idle time (Prob Idle) and average dropping of requests (Avg Drop). The rows represent the five agents and the internet. (IntN). From the values it is observed that the number of negotiation services dropped is high in Agent 2 and in the Internet. Hence these two resources are identified as the bottleneck resources. To solve this problem, we conducted the

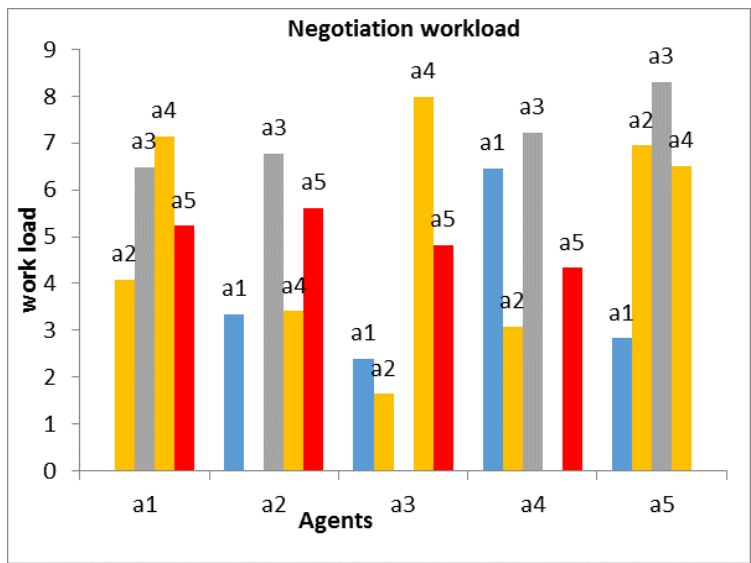

Figure 2: Agents V/S Workloads.

\begin{tabular}{|l|l|l|l|l|l|}
\hline & $\begin{array}{l}\text { Avg } \\
\text { Resp } \\
\text { Time }\end{array}$ & $\begin{array}{l}\text { Avg } \\
\text { Serv } \\
\text { Time }\end{array}$ & $\begin{array}{l}\text { Avg } \\
\text { Wait } \\
\text { Time }\end{array}$ & $\begin{array}{l}\text { Prob } \\
\text { Idle }\end{array}$ & $\begin{array}{l}\text { Avg } \\
\text { Drop }\end{array}$ \\
\hline Agt 1 & 0.003 & 0.003 & 0.0 & 0.342 & 0.0 \\
\hline Agt 2 & 0.607 & 0.021 & 0.586 & 0.047 & 0.830 \\
\hline Agt 3 & 0.006 & 0.006 & 0.0 & 0.196 & 0.0 \\
\hline Agt 4 & 0.008 & 0.007 & 0.001 & 0.181 & 0.004 \\
\hline Agt 5 & 0.016 & 0.013 & 0.002 & 0.218 & 0.005 \\
\hline IntN & 0.060 & 0.021 & 0.586 & 0.047 & 0.830 \\
\hline
\end{tabular}

Table 2: Simulation Result for the configuration C1.

sensitivity analysis by considering different configurations and are presented in the next section.

\subsection{Sensitivity analysis}

Simulation of the behavior of the resources is carried out by considering the configurations $\mathrm{C} 1$ to $\mathrm{C} 6$ is as follows. C1:-Processing speed of CPU is 2000, and the Internet speed assumed is 96 .

C2:-Processing speed of CPU is 3000 , and the Internet speed assumed is 96 .

C3:-Processing speed of CPU is 4000, and the Internet speed assumed is 96 .

C4:-Processing speed of CPU is 2000, and the Internet speed assumed is 146 .

C5:-Processing speed of CPU is 3000 , and the Internet speed assumed is 146 .

C6:-Processing speed of CPU is 4000, and the Internet speed assumed is 146 .

The results of the different simulation runs are presented in the form of tables. The results obtained for Agent 1 for the different configurations considered is presented in Table 3. The maximum time taken by the Agent 1 to respond is 0.036 in the configuration $\mathrm{C} 4$ and minimum time taken to respond is 0.003 with configuration $\mathrm{C} 1$. The waiting time in Agent1 is also maximum for the configuration $\mathrm{C} 4$. This is due to the configuration of $\mathrm{C} 1$; the number of negotiation services dropped is more due to the low configuration of the 
Internet. Hence the number of negotiation services that are processed by Agent 1 is less compared to other configurations. In configuration $\mathrm{C} 4$, the processing speed of the Internet is increased so that the negotiation services by Agent 1 are more.

\begin{tabular}{|c|l|l|c|l|c|}
\hline \multicolumn{6}{|c|}{ Agent 1 } \\
\hline & $\begin{array}{l}\text { Avg } \\
\text { Res } \\
\text { Time }\end{array}$ & $\begin{array}{l}\text { Avg } \\
\text { Serv } \\
\text { Time }\end{array}$ & $\begin{array}{l}\text { Avg } \\
\text { Wait } \\
\text { Time }\end{array}$ & $\begin{array}{l}\text { Pro } \\
\text { Idle }\end{array}$ & $\begin{array}{l}\text { Avg } \\
\text { drop }\end{array}$ \\
\hline C1 & 0.003 & 0.003 & 0 & 0.342 & 0 \\
\hline C2 & 0.02 & 0.019 & 0.001 & 0.196 & 0 \\
\hline C3 & 0.013 & 0.012 & 0 & 0.132 & 0 \\
\hline C4 & 0.036 & 0.032 & 0.004 & 0.135 & 0 \\
\hline C5 & 0.017 & 0.017 & 0 & 0.271 & 0 \\
\hline C6 & 0.016 & 0.015 & 0.001 & 0.137 & 0.003 \\
\hline
\end{tabular}

Table 3: Simulation results obtained for Agent 1 with different Configuration.

The results obtained for Agent 2 for the configurations considered are tabulated in the Table 4 . Agent 2 has taken the maximum time 0.607 to respond under Configuration $\mathrm{C} 1$ and the minimum time to respond is 0.009 with configuration C5. Figure 21 presents the average dropping of requests and probability of idle time of Agent 2. The maximum number of requests is dropped in configuration $\mathrm{C} 1$. The maximum waiting time for the requests is observed with configuration $\mathrm{C} 1$. This has happened because Agent 2 has received more requests.

\begin{tabular}{|l|l|l|l|l|l|}
\hline \multicolumn{7}{|c|}{ Agent 2 } \\
\hline & $\begin{array}{l}\text { Avg } \\
\text { Res } \\
\text { Time }\end{array}$ & $\begin{array}{l}\text { Avg } \\
\text { Serv } \\
\text { Time }\end{array}$ & $\begin{array}{l}\text { Avg } \\
\text { Wait } \\
\text { Time }\end{array}$ & $\begin{array}{l}\text { Pro } \\
\text { Idle }\end{array}$ & $\begin{array}{l}\text { Avg } \\
\text { drop }\end{array}$ \\
\hline C1 & 0.607 & 0.021 & 0.586 & 0.047 & 0.83 \\
\hline C2 & 0.02 & 0.15 & 0.004 & 0.108 & 0.005 \\
\hline C3 & 0.01 & 0.009 & 0.001 & 0.123 & 0 \\
\hline C4 & 0.023 & 0.018 & 0.005 & 0.115 & 0.005 \\
\hline C5 & 0.009 & 0.008 & 0.001 & 0.159 & 0 \\
\hline C6 & 0.01 & 0.009 & 0.001 & 0.133 & 0 \\
\hline
\end{tabular}

Table 4: Simulation results obtained for Agent 2 with different Configuration

The results obtained for Agent 3 for the configurations considered are presented in Table 9.5. Agent 3 has taken the maximum time 0.118 to respond under Configuration $\mathrm{C} 4$ and the minimum time to respond is 0.003 with configuration $\mathrm{C} 5$. The average dropping of requests and probability of idle time of the Agent 3 is plotted in Figure 23. The maximum number of requests is dropped in configuration $\mathrm{C} 4$. The maximum waiting time for the requests is observed in configuration $\mathrm{C} 4$ for Agent 3 .

\begin{tabular}{|l|l|l|l|l|l|}
\hline \multicolumn{7}{|c|}{ Agent 3 } \\
\hline & $\begin{array}{l}\text { Avg } \\
\text { Res } \\
\text { Time }\end{array}$ & $\begin{array}{l}\text { Avg } \\
\text { Serv } \\
\text { Time }\end{array}$ & $\begin{array}{l}\text { Avg } \\
\text { Wait } \\
\text { Time }\end{array}$ & $\begin{array}{l}\text { Pro } \\
\text { Idle }\end{array}$ & $\begin{array}{l}\text { Avg } \\
\text { drop }\end{array}$ \\
\hline C1 & 0.006 & 0.006 & 0 & 0.196 & 0 \\
\hline C2 & 0.008 & 0.008 & 0.001 & 0.14 & 0 \\
\hline C3 & 0.094 & 0.052 & 0.042 & 0.083 & 0.073 \\
\hline C4 & 0.118 & 0.06 & 0.059 & 0.082 & 0.102 \\
\hline C5 & 0.003 & 0.003 & 0 & 0.255 & 0 \\
\hline C6 & 0.055 & 0.033 & 0.022 & 0.099 & 0.044 \\
\hline
\end{tabular}

Table 5 Simulation results obtained for Agent 3 with different Configuration.

The Table 6 presents the results obtained for Agent 4 for the different configurations considered Agent 4 has taken the maximum time 0.033 to respond under Configuration $\mathrm{C} 3$ and the minimum time to respond is 0.008 with configuration $\mathrm{C} 1$. The maximum number of requests is dropped in the configuration $\mathrm{C} 3$. The maximum waiting time for the requests is observed with configuration $\mathrm{C} 3$.

\begin{tabular}{|l|l|l|l|l|l|}
\hline \multicolumn{7}{|c|}{ Agent 4} \\
\hline & $\begin{array}{l}\text { Avg } \\
\text { Res } \\
\text { Time }\end{array}$ & $\begin{array}{l}\text { Avg } \\
\text { Serv } \\
\text { Time }\end{array}$ & $\begin{array}{l}\text { Avg } \\
\text { Wait } \\
\text { Time }\end{array}$ & $\begin{array}{l}\text { Pro } \\
\text { Idle }\end{array}$ & $\begin{array}{l}\text { Avg } \\
\text { drop }\end{array}$ \\
\hline C1 & 0.008 & 0.007 & 0.001 & 0.181 & 0.004 \\
\hline C2 & 0.018 & 0.016 & 0.002 & 0.125 & 0 \\
\hline C3 & 0.033 & 0.025 & 0.008 & 0.116 & 0.011 \\
\hline C4 & 0.032 & 0.025 & 0.007 & 0.116 & 0.009 \\
\hline C5 & 0.014 & 0.013 & 0.001 & 0.179 & 0.004 \\
\hline C6 & 0.015 & 0.013 & 0.002 & 0.118 & 0 \\
\hline
\end{tabular}

Table 6: Simulation results obtained for Agent 4 with different Configuration.

The Table 7 presents the results obtained for Agent 5 for the different configurations considered. Agent 5 has taken the maximum time 0.07 to respond under Configuration $\mathrm{C} 4$ and the minimum time to respond is 0.016 with configuration $\mathrm{C} 1$ and $\mathrm{C} 5$. The maximum number of requests is dropped in the configuration $\mathrm{C} 4$. The maximum waiting time for the requests is observed with configuration $\mathrm{C} 4$.

It is observed that the response times of Agent 3, Agent 4 and Agent 5 in the considered configuration are closer to each other and only a few numbers of negotiation services are dropped. Maximum response time is experienced with Configuration $\mathrm{C} 3$ and $\mathrm{C} 4$ and observed that the dropping of requests in the Internet is the least for the configurationC 3 and $\mathrm{C} 4$. Lowest Response time is in C1 for Agents A1, A3, A4, A5 but experienced highest number of dropping in the requests. The behavior of Agent 2 is observed different compared to all the other agents' behavior. The reason can be that the average workload of Agent 2 is less compared to the workload of other agents, because of that Agent 2 could execute all the negotiation 


\begin{tabular}{|l|l|l|l|l|l|}
\hline \multicolumn{7}{|c|}{ Agent 5 } \\
\hline & $\begin{array}{l}\text { Avg } \\
\text { Res } \\
\text { Time }\end{array}$ & $\begin{array}{l}\text { Avg } \\
\text { Serv } \\
\text { Time }\end{array}$ & $\begin{array}{l}\text { Avg } \\
\text { Wait } \\
\text { Time }\end{array}$ & $\begin{array}{l}\text { Pro } \\
\text { Idle }\end{array}$ & $\begin{array}{l}\text { Avg } \\
\text { drop }\end{array}$ \\
\hline C1 & 0.016 & 0.013 & 0.002 & 0.218 & 0.005 \\
\hline C2 & 0.022 & 0.018 & 0.004 & 0.211 & 0.004 \\
\hline C3 & 0.025 & 0.02 & 0.005 & 0.107 & 0.002 \\
\hline C4 & 0.07 & 0.045 & 0.026 & 0.091 & 0.03 \\
\hline C5 & 0.016 & 0.013 & 0.003 & 0.128 & 0.008 \\
\hline C6 & 0.025 & 0.021 & 0.004 & 0.126 & 0 \\
\hline
\end{tabular}

Table 7: Simulation results obtained for Agent 5 with different Configuration.

\begin{tabular}{|c|c|c|c|c|c|}
\hline \multicolumn{7}{|c|}{ INTERNET } \\
\hline & $\begin{array}{l}\text { Avg } \\
\text { Res } \\
\text { Time }\end{array}$ & $\begin{array}{l}\text { Avg } \\
\text { Serv } \\
\text { Time }\end{array}$ & $\begin{array}{l}\text { Avg } \\
\text { Wait } \\
\text { Time }\end{array}$ & $\begin{array}{l}\text { Pro } \\
\text { Idle }\end{array}$ & $\begin{array}{l}\text { Avg } \\
\text { drop }\end{array}$ \\
\hline C1 & 0.0607 & 0.021 & 0.586 & 0.047 & 0.83 \\
\hline C2 & 0.088 & 0.001 & 0.087 & 0.051 & 0.413 \\
\hline C3 & 0.025 & 0.021 & 0.004 & 0.033 & 0.068 \\
\hline C4 & 0.07 & 0.004 & 0.066 & 0.048 & 0.22 \\
\hline C5 & 0.163 & 0.004 & 0.159 & 0.05 & 0.674 \\
\hline C6 & 0.068 & 0.004 & 0.064 & 0.048 & 0.198 \\
\hline
\end{tabular}

Table 8: Simulation results obtained for Internet with different Configuration.

requests it received. Also we observed that when the Internet speed is increased the dropping of requests reduced which gives the inference that many negotiation requests are executed by the agents successfully.

\section{Summary}

In this work, we presented a methodology to model the negotiation between the agents and predicting the performance of the system. We presented methodology to: i) develop a mathematical model for the workload of negotiation scenarios over a time horizon, ii) modeling the execution environment, iii) and iv) analyzing the execution environment for variations in resource configurations. The sensitivity analysis is done by considering modification in the resource configuration one at a time, and it also describes bottleneck resources. The output showed that how the different configurations of resources affect the response time of the agents.

\section{References}

[1] A.Dorri, S. S. Kanhere and R. Jurdak, "Multi-Agent Systems: A Survey," in IEEE Access, vol. 6,pp.28573-28593,2018.

https://doi.org/10.1109/ACCESS.2018.2831228

[2] Jing Xie \& Chen-Ching Liu (2017) Multi-agent systems and their applications, Journal of
International Council on Electrical Engineering, 7:1,188-97,DOI:10.1080/22348972.2017.1348890 https://doi.org/10.1080/22348972.2017.1348890

[3] Wooldridge, M.: An Introduction to Multi-Agent Systems. John Wiley Sons, Inc. New York, NY, USA (2001)

[4] Ebrahim AlHashel, "A Conceptual agent Cooperation Model for Multi-agent Systems' Team Formation Process", Third 2008 International Conference on Convergence and Hybrid Information Technology, $\quad$ pp. 12-20,2008. https://doi.org/10.1109/ICCIT.2008.367

[5] Connie U.Smith and Lioyd G. Williams., "Building Responsive and Scalable Web Applications." December 2000. Proceedings CMGC.

[6] S. Balsamo, A. D. Marco and P. Inverardi., "ModelBased Performance Prediction in Software Development: A Survey." IEEE Transactions on Software Engineering, May 2004, Vols. Vol. 30, No.5. https://doi.org/10.1109/TSE.2004.9

[7] V. Cortellessa and R.Mirandola., "Deriving a Queueing Network Based Performance Model from UML Diagrams." s.l. : ACM Proc. intl, 2000. Workshop Software and Performance. pp. pp. 58-70. https://doi.org/10.1145/350391.350406

[8] Ajitha S, Suresh Kumar T.V, Rajanikanth K. A Quantitative Framework for early prediction of Cooperation in Multi-Agent System. ICTACT Journal on Soft Computing 2013; 587-595, DOI: 10.21917/ijsc.2013.0085. https://doi.org/10.21917/ijsc.2013.0085

[9] S. Ajitha, Dr.T.V.Suresh Kumar, Dr.K.Rajanikanth, "Artificial Neural Network Approach for predicting performance of MAS using SPE approach". International Journal of Software Engineering, Volume6, No.2,pages 3-20, July 2013.

[10] S. Ajitha, Dr.T.V.Suresh Kumar, D.E.Geetha, Dr.K.Rajanikanth "Modeling Co-operative Index of Multi-Agent Systems using Execution Graph". Proceedings of International Conference on Advances computing in Intelligent Systems and Computing Volume 174,2012, pp41-48, Springer,DOI:10.1007/978-81-322-0740-5. https://doi.org/10.1007/978-81-322-0740-5

[11] S. Ajitha, Dr.T.V.Suresh Kumar, D.E.Geetha, Dr.K.Rajanikanth "Early Performance Prediction of Co-operative Multi-Agent Systems" procedia Engineering,38(2012)3037-3048,DOI:10.1016/ j.proeng.2012.06.354. https://doi.org/10.1016/j.proeng.2012.06.354

[12] Ye Chen, Yun Peng, Tim Finin, Yannis Labrou, Bill Chu, Jian Yao, Rongming Sun, BobWillhelm, Scott Cost, A negotiation-based Multi-agent System for Supply Chain Management ,In Proceedings of Agents 99 Workshop on Agent Based DecisionSupport for Managing the Internet-Enabled SupplyChain.

[13] T. Wong, C. Leung, K. Mak, and R. Fung, "An agent-based negotiation approach to integrate process planning and scheduling," International 
Journal of Production Research, vol. 44, no. 7, pp. 1331-1351,2006.

https://doi.org/10.1080/00207540500409723

[14] W L Yeung, Performance of Time-Bound Negotiation in Agent-Based Manufacturing Control, Proceedings of the World Congress on Engineering 2012 Vol III WCE 2012, July 4 - 6, 2012, London, U.K.

[15] D.E Geetha, T.V. Suresh Kumar, Performance Modeling and evaluation of Distributed Systems, Ph.D thesis, Visvesvaraiah Technological University, Karnataka, 2012 